\title{
2007 Colin Roderick Lecture
}

\section{Nicolas Rothwell}

\author{
James Cook University
}

Let me thank my audience for coming to listen to me today: let me thank the Foundation for Australian Literary Studies for inviting me to give this year's Colin Roderick Lectures.

I like to think that Professor Roderick would have looked kindly on the choice of a lecturer drawn from the bleak, ambiguous demi-monde where journalism and literary endeavours meet - for he was involved, as many of you will know, during his days as an editor at Angus and Robertson, in the celebrated libel case in 1961 over "The Bandar-Log," a novel, still unpublished, by the distinguished Canberra press gallery journalist, Alan Reid. Roderick's own writings had a strong influence on me at a particular point in my path as an author: but the one act of his that resonates most strongly in my thoughts is the decision he made, 40 years ago, to establish a centre for the study of Australian writing here in the North.

I, like Colin Roderick, believe that the north exists, and is a specific place, with a literature and a perspective of its own: and I have spent long hours, in hazy discussions under twirling fans, or round isolated camp-fires, trying to frame the story of the tropics and remote Australia; trying to gauge the impact of that story on my mind and my character, and on the voices of other writers and artists who live and work in North Queensland, the Northern Territory, the Kimberley and Pilbara regions - the swathe of Australia many dream of, and few see for any length of time: the region my old editor Frank Devine believes we should christen with the name of Capricornia.

Of course I am aware of the geographic gradient of these lectures in past years. As I look down the rather distinguished list of former speakers, it is hard not to notice that they are almost uniformly drawn from the ranks of authors and public intellectuals resident in southern cities: enlightened souls enticed, during the cool season of the year, into flying north to Townsville and Cairns to shed some wisdom: men and women largely innocent of the buildup, and the wet, and the rhythms of this part of the continent. With me, the situation is different: I live in Darwin, in the Territory - a place that lies far beyond the realms of writing, I suspect, in the minds of most members of the metropolitan cultural world. It is the margin; it is the periphery; its role, I often feel, is as a marker of literature's boundary-line - of the 
edge of letters. Writing can be brought back from there, on occasion, perhaps, but only rarely is the angle of view from this northern frontier outpost expressed. In the time we spend together this evening, I would like to describe to you not just some thoughts prompted by that perspective, but also some of the feelings that fill me in my travels across the north, and the pull that first drew me into this country: I would like to paint for you in words the flash of the horizon, and the shimmer of the sand-dunes, and how they have changed me: and also to tell you some of my ideas about the evolution of art, and about form in writing, and the way that I believe it fits with sense of place: I even hope to hint at an alternative literary history of Australia, a hidden history, in which the central and western deserts, and the savannahs and the tropics, play their part.

Sometimes it's best, when talking about such things, and the links that stretch between them, to proceed diagonally, almost by stealth, looping round, and making several passes, like a hawk on the wing. Perhaps I can edge into my subject by touching for a moment on some memories of the landscape of far north Queensland, and the impact it made on me, when I first began frequenting this part of the world as an adult, after many years away from Australia.

I can still remember with great precision my flight in to Townsville one afternoon, just over a decade ago, after a series of driving journeys through the Channel Country, and the basalt inlands, and the winding river valleys of Cape York. All that landscape was in drought; it was brown, and grey, and nothing was moving, and the whole state seemed to be blanketed by thick, unyielding cloud: I remember the low, long approach to Townsville airport, and my staring through the curved cabin window out at veils of rain, beginning to tumble earthwards, looking much like the drawn-back curtains of a miniature apocalypse, and evaporating even as they fell: I can picture myself driving northwards, beyond Cooktown, into the scrubby country of the eastern Cape, and trying as I went to fit its elusive gum-trees and pale soils into what I knew of plateau landscapes elsewhere in Australia: and I see myself gazing up in wonder at the lighthouse mountain, with its marble summit outcrop that guards the Coen road. Most of all, though, my memories of those trips come to centre on a series of ill-advised sorties I made, alone, by Landcruiser, out to the Palmer River, where my great-grandfather died, and was buried, in the late nineteenth century goldrush years: but, as those of you who have been to Maytown, and braved the rough, corrugated tracks between its guardian conical hills, already know, there are few traces remaining from that time: the past, in remote 
Australia, even the written past, has a habit of swiftly becoming invisible, so that its traces can only be discerned or recovered with the utmost expenditure of attention and loving care.

When I began making those excursions, I already had well-developed ideas about literature, and the novel, and the place and scope of narrative as a mirror of modern life. I had been a foreign correspondent for many years, and had worked around the world: in the Americas, the Pacific, South-East Asia, and Western and Eastern Europe. I had been greatly marked by my experiences during the golden year of 1989, when the communist regimes of the Warsaw Pact fell, and the Berlin Wall came down: and I had also seen the collapse of the Soviet Union, and the Balkan civil wars: it was clear to me, even as those events were unfolding, that they exceeded the descriptive reach of journalism - and I still feel that they have yet to pass fully into history. I understood the convulsive end of European communism not merely as a series of political revolutions, but as a drama of power and dictatorship, enacted in the minds of individuals: and it was this aspect of the story of those times that I dwelt on in a novel I wrote some years after 1989. That book, "Heaven and Earth," which I worked on in various places in western Europe and the Caribbean, during a somewhat nomadic phase of my life, was very much a European-accented novel of ideas, and it in turn reflected European beliefs about the novel as the supreme vehicle for conveying internal experience. Shortly after I completed that manuscript, I came back to Australia: At the time, I believed that I was returning because I had realized I was in danger of having no home at all, of falling, like many foreign correspondents, into a limbo of extraterritoriality - but now I look back on that time, and my younger self, I wonder whether I came back then because I felt I had completed a kind of preliminary international education, and had explored not only the politics and history of modern Europe, but the European literary tradition as well, from the inside - and it is to that tradition that I now, for a moment, turn.

I want to sketch before you, rapidly, a set of vast suspicions - ideas which have stayed with me over the years, and which I will simply assert as a collection of truths, even though each is only partial, and conditional, and even though each deserves a lecture or a substantiating book of its own - and I lay them out in the belief that they may help illuminate the landscape within which Australian writing, and the writing, above all, of the north and the continent's remoter regions seems to me to rest. (I am conscious of the degree of my self-possession, in daring in this way to diagnose the condition of Australian letters before the members of a foundation dedicated to that task - but, as my first literary editor, the self-effacing Norman 
Thomas di Giovanni, who devoted his best years to the Argentinian fabulist Jorge Luis Borges, once told me, very wisely: "With every author, you have to put up with something.") Let me, then, give you a glimpse of my world-view.

I have come to feel that writers working in the western tradition today confront a dreadful, and largely unacknowledged, dilemma: we stand at the end of European civilization. Not at its mid-point, or in the days of its autumnal decline, but at the end. We cannot even bring ourselves to mention this overwhelming truth: we clasp it to ourselves like a family secret, and find new webs of words to hide our fate. But we know, in some kernel of ourselves: the brief age of European economic and political and cultural ascendancy, a time of less than half a millenium, which gave us bourgeois society, and colonial empires, and the novel, has passed. It was already passing at the start of the twentieth century, the point at which American cultural and economic vigour emerged to dominate the globe. The tragedies of the world wars, the holocaust of European Jewry and the communist decades in the eastern half of the continent placed the full stop at the end of this age. I do not argue that there is no art or culture being made in Europe: on the contrary, art, design and culture are almost all that remain. What I argue is that we are in a period of European decadence - and this has profound reverberative implications for Australia, as a society founded on the European cultural model, and for Australian writing as well. Every one of us knows how deeply Australian literature has been influenced and conditioned by the English template: Australian ways of seeing, thinking, naming, and being are only just emerging from the shadow of the colonising, continent-taking act. And one of the unspoken assumptions of Australian culture has been the acceptance of the novel as the ideal written form for explaining and illuminating national life: the novel, like democracy, has been seen as a universal good. Among critics, accordingly, there has been a constant search for the great Australian novel: literary souls scan the publishing horizon, while creative university students and oppressed journalists sitting at their lonely desks dream of confecting an imaginary, yet tellingly recognisable version of the world. All this is based on the theory, buttressed by the evident production of many strong novels, that Australia is a novelish kind of place: a continent suitable for developed fiction. I am not so sure.

To change the angle of flight for an instant, and loop back from another direction to this disquieting subject, the novel as device for story-telling is today a hundred thousand things. It is many traditions, by now, in many lands: and as Australia has travelled away from its 
imperial, anglocentric heritage, so its idea of what might be appropriate or fitting in its literature has also shifted. The English novel is a majestic forebear to claim: and one can still see its fading outlines in the DNA of Australian novels, in their trajectory down the decades, beginning with their portmanteau social broadbrush, and descending to their present sharp attention to the interior life. But I believe the English tradition, for all its richness, and its glorious eccentricity, bequeaths certain legacies: I find in the classical "great tradition" a distinctive centre of gravity - a particular kind of political and social intelligence, an interest in towns and cities and communities, a commitment to realism as a way of conceiving the world. This is, of course, a form of intelligence well-suited to taking possession and charting and shaping new terrain. There is, though, another European tale-writing, story-making tradition, to which I feel myself close, perhaps unsurprisingly, since the background of my mother's family lies in Bohemia, and I am steeped in the music and writing and art and architecture of that country, and that cultural region, Mitteleuropa, which underwent a long series of privations and divisions in the course of the century that has just passed: privations and purges so deep that the spirit of that culture may well persist into our time only in memory. If I mention a handful of names - those of Kafka and Hoffmann, of Mandelstam and Bruno Schulz, I have probably delineated this hybrid terrain for you with a degree of precision: it is a terrain and tradition that is at home with the uncanny, and which has a less than confident tie to realism, and the assumption that the world is all that is the case: and it is a tradition that I have found both consoling and well adapted to the ideas and imaginings that stir inside me in my journeys and investigations in the Centre and the North.

These musings of mine about the novel lead me to a broader theory, if I can give such a name to an idea that is largely instinctual in its origin. I believe art has a kind of carrier-wave of energy, which is alive in the world, and surges here and there, and expresses itself in the froth and spume of societies: and the front of that wave, the bow-wave of creative force, survives always, but changes constantly: it moves through art forms, picks them up, exalts them, then casts them down, much like the surf of a wave-front, rising, breaking and rushing by. Hence the striking phenomenon that the very earliest moments of a literary or creative tradition are often its highest peaks: Homer, Shakespeare, Bach, Haydn. Within forms, too, I believe this pattern holds, and further, it seems to me that there is a natural tie between artistic styles and the phases that predominate in social worlds. The novel, again, finds its early, spectacular flowering in the eighteenth century, and reaches a crescendo in the industrial age, in the canon of works that we still gaze up towards today as we might stare out at a range of airless, 
unattainable peaks: Balzac, Stendhal, Tolstoy, Dickens. After this, the novel enters its era of hypertrophy, in the form of books so brilliant and encyclopaedic and excessive they remain largely unread: Joyce's Ulysses, Musil, Proust - nor is this a pattern without distant echo in our own literary history. The thing is that the wave of energy passes on: the art form becomes mature, and enters into a long, pleasant, comfortable decline - a decline that can be marked by the highest sophistication and intelligence, an intelligence which is self-conscious, and critical, and largely devoted to concealing the plight of the tradition from itself.

When I was first formulating these thoughts, a few years ago, I came across a striking interview with the Russian pianist Mikhail Pletnev, a performer whom I greatly admire. Pletnev is also a composer, and thus knows the fabric of the musical tradition intimately from both sides of the weave. His performances are marked out by a kind of resolved, desperate clarity: a relentless graduation of sound, and there is something similar in his analysis of the state of musical culture. He believes the age of classical music has come to an end, and we are now in its post-history, an Alexandrian time, a time of reinterpretation, and that only. For Pletnev, "There were certain circumstances which helped classical music to be born, then it hits the heights. It's like a mountain range - you don't know exactly where it starts, but suddenly you are in the heights. Then you go on, then you are among smaller hills, then no more mountains - it is finished." This is a salutary reminder that things do not always persist: the landscape is not only capable of changing: in time, inevitably, it must.

The energy wave is always moving on: it flows on: it passes from the novel to other forms of writing: forms collapse upon themselves, and are reborn. There is always a place where the fervour of creation sits: and I suspect a clear view of the century just passed would trace the movement of the shock-wave of artistic energy in writing, moving away from the novel form: moving to genre, to memoir, perhaps to hybrid narrative, just as it has moved from stage to film to video game; from impressionism in painting into and past modernism; from photography into the swelling murk of digital creation, and on, towards a looming future for the visual arts that I find hard to discern.

And just as I believe societies in their evolution shelter certain art-forms, so I am inclined to believe that places, and even continents, nurture their own kinds of art. The novel, for all its suppleness, and its splendour as a reflection of the internal self and that self's social interplay, for all its mastery of subjective time, seems to me a fundamentally European, western affair even in its current world-wide dissemination. It is a form linked to seasons, to notions of 
progress, it believes in beginnings and ends, in love, and drama: it does not admire nature, and earth: it is not a mirror of eternity, and repetition, but of surprise - and of man.

Such were my half-formed thoughts, at the time when I came back Australia, after long exposure to war and revolution, in the very month when John Howard secured his position as Prime Minister. Some instinct prompted me to embark almost at once on a set of travels across remote parts of regional Australia, and quickly it became clear to me that this was the aspect of the country that answered to my particular cast of mind and to the leanings of my heart. I have tried often to describe this conversion experience: perhaps it stemmed from some half-remembered childhood exposure to the bush landscape, or some need for knowledge of an uncharted world - but I feel sure that much of its impact on me was due to the companions and precursors whom I found my way to in those years: literary precursors, and men and women whose words and silences helped guide me through the landscape. I think of Ada Miller, the matriarch of Camooweal, who opened up for me the green horizons of the Barkly: I think of Darcy Redman, the house intellectual of Mount Isa, whose symphonic understanding of the Selwyn Ranges and the Gulf country and man's place there lodged so deep in my thoughts that I can still bring to mind the phrases and the figures of his speech he employed at our first meeting, more than a decade in the past. I remember the artist Ray Crooke, who seemed to have been put on earth specifically to paint the texture of the savannah landscapes surrounding the lost township of Chillagoe; I recall Percy Tresize, the rock art pioneer of Laura and the surrounding Cape country, a compulsive story-teller, whom I always seemed to encounter just as he was undergoing episodes of deep ordeal, and whose bush camp, with its attendant dingos, resembled in my imagination a stage-set, surrounded by a stone amphitheatre from which painted ancestral figures stared gravely down.

But the guides that led me across the continent in those days were also written ones: this was the time that I made the acquaintance of the great explorers, and their narratives, which, doubtless, I would have despised when my tastes in literature were more avant-garde. It became clear to me, as I read, that there was a distinctive pace and rhythm to their writing: I began to think of their journals as tales dictated by the landscape, given breath by country and I often designed my reporting life so as to be able to retrace their uncertain steps across the deserts and the scrublands of the north. First among these guides was Ludwig Leichhardt, whose Journal of an Overland Expedition in Australia became a key to my understanding of the bush: and I soon found my way from that work to Colin Roderick's life portrait: 
"Leichhardt - The Dauntless Explorer" - a book which gave me a point of entry to form my own reflections on Leichhardt's experiences, his scientific mission, his romantic, Europeanaccented way of conceiving the landscape, his sense of the sublime. In the months and years when I was following in the paths of the explorers, I was also beginning to write about Australia, and I found myself ever more struck by the place of the story, the yarn, the constantly renewed and communicated thread of narrative, making its way between people, as if tales were necessary to the land, and gave it life and meaning: and listening to stories helped deepen my awareness of the past's weight, and the vanished presence of those who had been in the empty reaches of the deserts that I was seeing, or the deep fissures of the Stone Country in West Arnhem Land, or the Pilbara's river gorges and silent, abandoned homesteads.

After some while, I plotted out and began writing a novel of modern Australia: it did not go well, for reasons which were doubtless related to the circumstances of my world: but then, what book ever does go well? In time, it became obvious to me, as I wrote, that I had misgivings about the form of the novel, and its capacity to encompass my overarching sense of Australia. Of course I was well aware of the thriving literary domain around me; of the many novels and stories being written in different styles: novels that were modish, and intelligent, and as brilliantly distinctive and individuated as the fictions being produced in ever greater numbers in other anglophone societies around the world. But the writers who most attracted me in those days were working in another vein: through the convenient membrane of journalism, I was able to spend a little time with the poet Les Murray, and with the polymorphous Eric Rolls, both authors possessed by a strong connection to place: and as I look back now, I wonder whether I was not heartened or even influenced by my close reading of their works - the animal poetry Les Murray wrote in some of his darker times, for instance, or the portrait of the Pilliga Scrub contained in Rolls' "A Million Wild Acres."

At any event, I was able, after prolonged immersion in these and other narratives, and continual travels in regional and metropolitan Australia, to write a book with a closely organized, but not completely fictive structure, devoted to the stories and the love of stories that I had encountered on my way: and that book, "Wings of the Kite-Hawk," now orients me on my further journey towards the various dark horizons that wait for us in life.

At this point, I feel it might be time for me to retreat a little from my recollection of my own experiences - for what author is an omniscient, or even a reliable authority about himself? - 
and make a quick pass at a slightly higher level over the topography of Australian writing, and try to outline a broader pattern, in which my own tale might form at most an infinitesimal strand.

There is a familiar, consensual chronicle of Australian letters, which spans much of the past two centuries in an elegant, progressivist sweep - and I also see a subtle counter-story, which holds its own set of lessons about the interplay between history and imagination. Doubtless, scholars of the field, like Colin Roderick, and Peter Pierce, and Stephen Torre, and their southern colleagues would discern a much more multiplicit braid: but let me outline my quick schema for you.

I picture the moving channel of Australian literature bathed by several separate lights, which catch different aspects of its onward flow: you can read the story through the turbulence of politics, or economics, at the level of society or sensibility: you can feel the pressure of outside literary influences, and the shaping experiences that come to act on individuals. It is a story that takes its rise in the first decades of the nineteenth century, when European writers were lifted up by the wild gale of romanticism - and there is a struggle, even among the early explorers, Leichhardt, of course, and Mitchell, both of them high intellectuals and enthusiasts of the literary sublime, to read the landscape in romantic terms: a struggle that often falls back on itself in disappointed failure. Soon there is a drive, in the later part of the century, to shape and define the new Australian character through writing, and this leads to memoir narratives, to verse, to the first Australian-penned novels, and, around the time of federationera nationalism, to a form I regard as particularly characteristic of the continent: I can only call it the yarn, the story the main point of which is in the telling. The supreme exponent of this form is the Banjo, whose name I speak with the deepest admiration, a hero to me - a man who respected no boundary of genre or style. After the end of the Great War, the properly literary era begins, a self-conscious time, when Australian writers seek to fix - chiefly through the novel - their distinct voice. What seems to me most noticeable about this time is the quest that was emerging then for a position in the world: the writers of mid-century, whether their experience was that of a Xavier Herbert or Patrick White, were set on international renown; their Australian fame almost depended on, and was greatly bolstered by, their overseas acceptance: and to a large degree this pattern seems to me to hold to this day. The dominant trajectory of Australian letters, then, its grand narrative, is one of isolated birth, and somewhat anxious development, succeeded by a rejoining of the world, a 
triumphant return to the fold: and this model entails certain unusual consequences: the appearance and ascendancy, as "licensed explainer," of the expatriate litterateur; the keen attention Australians pay to accounts of their country written by outsiders; the swift penetration of fashions and influences from the realms of British and American publishing. Such trends, of course, throw up their own counter-patterns, and the most critical of these for my argument is a trend I would label "novelistic nationalism" - novels which are recognisably, defiantly Australian come into favour, and their distinctive tone and setting even allows them a small niche in the international bazaar for strong spices and foreign tastes. Their importance, though, their psychological importance is in their employment - their domestication - of the novel form, which remains the respectable exemplar of literary achievement. And the novel, though the wave-front of energy may have long since left it, though its modern form has a commercial, stylistically conservative lean, thus becomes, over the past generation or so, a pillar of cultural nationalism, in common with Australian art and film: and one clue to the work the form is doing lies in the extraordinary present vogue for historical novels, for novels that probe and recast, in uneasy fashion, justifying themselves by their enlightened hindsight, the vexed record of Australia's settlement and conquest.

This brief account paints the path of Australian writing as an upward glide: and it has been a journey towards sophistication, towards self-awareness, towards the formation of a rich and intermeshed and well-funded, almost self-sustaining cultural establishment. Why, then, my hesitation, my slight sense of sadness as I describe this pattern of ascent? Why? I believe there is another Australian writing tradition: one that is original, distinctive, prompted by where we find ourselves - a tradition that is somewhat less noticed and less admired. It is a writing that tends towards the reduplicative and the understated, the mazy and the openended. It is the tradition that was first sensed and explored by Leichhardt, whose disappearance seems somehow very like its defiant foundation act. Its works are hybrid, and unreliable, and conform to no obvious canon - and yet they are instantly recognisable: they have a common stamp. I am thinking of books that come from many distinct fields, and were written in various ways, at various times: let me list a few, almost at random, for randomness seems fitting, and suits my purpose: There's "Tourmaline," by Randolph Stow; and Scott Cane's "Pila Nguru" and T.G.H. Strehlow's "Journey to Horseshoe Bend." There's Billy Linklater's "Gather No Moss," there's the biographic "Man from Arltunga," by Dick Kimber, and there's "Catalina Dreaming," a narrative of war-time flying boat service, written by my dear friend in Darwin, Andrew McMillan, who describes in this way the sound, one afternoon 
in late March 1943, of an air-raid siren heard by servicemen in Cairns: "It starts off low, like it's emerging from the mud flats, slithering through mangrove swamps, writhing like a taipan through this fetid fertile earth, feeding on rotten mangos and coconut husks and growing stronger by the second. The sound, that woeful keening of the sorry times, rises and flexes and rolls through the heat, slides along the weatherboard walls of houses high on stilts, seeps into deep dark balconies shrouded in bougainvillea. Louder still, it howls through the palms and poincianas and star-white clusters of frangipani. Shrieking, it bounces off the corrugatediron roofing and soars, an aural ribbon of grungy maroon twisting through this dense soggy air, wailing across a sleepy town draped with rumpled sheets of greasy grey cloud. Whining, it roller-coasters up restless jungle-clad mountains disappearing into mist, dives back down the scale carving out a swathe of panic and fear, and finally dies, pealing off to a sorrowful whisper through the cane fields."

I could dwell on this passage: on its sensual excess, its indulgent love of itself, its innocence and lack of artifice, its treatment of emotion and environment as one: but what I seek to single out is the deep structure of Andrew's "Catalina Dreaming," and other books like it from the extended shadow-family of place-bound writings, and tales that seem to spring up from the landscape like mists or ghosts.

Such works are set apart not so much by their obvious regionalism, or their nostalgic affection for a certain place or time, or even by their desire to populate and humanize the landscape - although this seems to me to be the secret motivation lurking in their hearts. They are works that tend to hold themselves away from the great world; they sometimes have a slightly provincial tone about them, even when they are pieces marked out by the deepest intellectual originality and force. They thrive in remote conditions, away from influence and fashion, and they signal to each other from vast distances: often, they remain quite unaware that they form an emerging pattern, a written filigree above the continent. There is about them a particular angle of attack, a fitting concordance between their shape and the way they speak. At times, they achieve that rarest thing: an unforced harmony of form and subject.

I could spread my argument further, and suggest to you that there are novelistic writers of great prominence: Tim Winton, Peter Carey, who yearn to rejoin this shadow tradition that they have travelled from. I could point you in the direction of verse, and even anthropological and historical narratives - Geoffrey Blainey's "Peaks of Lyell," for instance, stands in my thoughts as one of the purest achievements of Australian literature, even though it was tossed 
off by its author in a wild vernacular style, in his early 20s, and is concerned solely with the tale of a mining province in remote west Tasmania. What I have come to feel is that such writings as these need to be re-examined, much as an exploration geologist sifts the evidence of deep structure unfolding before him with each new batch of cores and samples that emerge into the light. I regard them not as eccentric outliers, rebel weeds that failed to take - but as emblems of the beckoning future - traces of an ore as yet unformed: the first glimmering stars in the dark sky of an authentic Australian literature.

The pattern of past cultures may provide us with some clues. Writing, in one important respect, tends to lag behind social and political developments: for all our conviction of the newness of everything we make and see, the creative domain has a tendency towards a formal conservatism - and one manifestation of this, I suspect, is the persistence and apparent success of old means of casting and conceiving the narrative art.

Let me give a quick illustration, drawn from the classical world, which is the one I have studied most. Ancient Athens, above all the Athens of the mid-5th century, is regarded as the furnace of western art: tragedy, comedy, history, oratory and philosophical dialogue all had their origin or first concerted development in that small city-state in those years, and radiated outwards, even to world-conquering Rome, where these Athenian forms remained the templates of literature for so long that the Latin poet Horace could write, in a line that became famous, and is rather dizzily self-referential: "Graecia capta ferum victorem cepit, et artes intulit agresti Latio." Defeated Greece conquered the savage victor and brought its arts to rough and ready Rome. Only after several centuries did art-forms original to Roman experience begin to appear: the love elegy, in the Augustan age, and, some while later, the picaresque fiction narrative, which found its first bloom on the empire's confused, provincial frontier, during the late second century AD. My point is that 200 years of national history, even in our age of accelerated velocity, is not a long time passed in the murky delta of literary evolution. We may not yet be in the golden, climactic era of Australian civilization: we may merely be in a post-settlement, post-colonial time, and the writings we see about us, chaotic, unsure, and energetic, seem to me to reflect that landscape. In fact I suspect that the history of Australian literature is only just beginning - and I believe we would be well advised to remain on watch, staring out to the horizon, searching for signs of new traditions, rather than aspiring purely to follow international best practice, and adopting the conformist virtues of Rome. 
At which point, let me, for the last time, pull back from my subject, and change the angle of approach. I have left out something: it is a large absence. I have made no mention of Aboriginal Australia, that constant subject of books and studies, that domain of strangeness, which has been so fruitful for generations of artists, intellectuals and self-exploring researchers in the sciences of man. I have said nothing at all about indigenous people: how they are written about, who writes about them, on what terms. I have not touched on the growing number of writers of indigenous background, and their varying approaches to life and art, and the hybrid promise lying in the multiple registers of contending experiences that make up modern Australia. Above all, I have said nothing about the story-world that preceded the arrival of western ways of writing: I have said nothing of the traditional indigenous realm, and how it figures in our minds.

I feel a great reticence on this front, and yet I think, in the flow of this lecture, there are some salient points to make. Readers of sensibility know the bitter truth: all depictions of traditional Aboriginal people in Australian fiction are embarrassingly awful, and devoid of plausibility or inward life. This is a striking fact, little discussed, for natural reasons. There are some obvious explanations: the depth of ignorance of Aboriginal societies that most authors of fiction radiate; the sentimentality and sense of responsibility writers feel on their shoulders when they approach this domain. But there is another aspect of the matter, which I would like to explore.

First, as a means of looping down towards my idea, let me tell you a story about a man I admired, W. C. Wentworth, the first Commonwealth minister with responsibility for Aboriginal affairs, who died four years ago. When I was in my late teens, I read in a scientific journal a note by Wentworth, who was already, at that stage, long retired from his political career. It was about the peopling of the Pacific, a subject that interested me greatly at that time. I wrote to Wentworth, who invited me to talk to him; very kindly, he took me to his club in Sydney, an environment where, I must say, we both seemed somewhat out of place, and we had a long, mazy conversation there, in the course of which he mentioned to me his conviction that certain Aboriginal song cycles were the equal, in their beauty and their structural perfection, of the Homeric epic poems: they gave breath and force to distant, legendary figures: you believed in them; you felt them at your side. We broke off soon after that, and I forgot to ask him which song cycles he meant. Life unfolded, I became a foreign correspondent, and only after many years did I come back to Australia: but I had remembered 
that exchange, and had paid special attention to Aboriginal song, and sacred dance, and had read what I could in that field. Some while ago, when I was travelling extensively through the north, I found out from a photographic colleague of mine, rather to my surprise, that Wentworth was still alive, and that he was living in Kuranda, above Cairns. I made contact with him again, and went to see him, and we had another long talk, with the rainforest, this time, as our background, instead of the bright sails of the Sydney Opera House. I reminded him of what he had told me, almost two decades before - and perhaps both of us were struck, at that point, by the marking beat of those two discussions in the rushing flow of time: at any rate, he said he must have been thinking of the Djanggawul song cycle, an austere and lovely creation poem from North-East Arnhem Land. Our conversation continued, and took an abrupt turn into transportation issues, for Wentworth was particularly interested by mass transit and city traffic planning. After some hours, I went back down the mountain to Cairns, and travelled on: and that was the last time I saw Wentworth - almost. Maybe a year before his death, when he was already in his early 90s, I remember catching sight of him in the middle of the Sydney rush-hour, at Town Hall station. I was plunging down into the depths of the lower platform level, and he went past me, riding the up escalator, clutching a note-pad close before him, gazing around at the melee of mass transit, and making quick, urgent notes with his pen. Such was W.C. Wentworth. And I have come to feel that the lengthy, reduplicative, metaphor-glutted song cycle he left me with, the Djanggawul, goes some way to explaining the resistance of Aboriginal society to serving as a suitable subject for fiction, or for the incoming eye.

I have been close, in recent years, not only to Yolngu families from Elcho Island, but to a number of desert people, who still sing their song cycles, and trace out on their country the exact paths of the creating ancestors - and it is a life-shaping experience to travel through the sand-dunes of the western desert, listening to old men singing in their rhythms the songs of each tree and rise and fold in the surrounding rocks as they pass by. I am tempted to say that such societies are not just remote from ours, but that they have a geometric stillness and elaboration, together with a quality of fancy, a developed imaginative fervour, which means they cannot be abstracted: you could not write a fiction about a desert society, and change a man's totemic affiliation, or his family, or any of the attributes that belong to him, without losing all the truth. And so it is with the Yolngu, in their precisely calibrated, interlocking worlds in Arnhem Land. They stand beyond fiction: whenever a novel is written about the 
Aboriginal domain, it is a frontier product: it is inevitably written from a western cast of mind.

Let me push on beyond this, further into the unsayable dark. Traditional Aboriginal society, which once ruled all the country of the North and Centre that I see and travel through, is shifting, undergoing metamorphosis, becoming something else. It is headed into the past: not that dynamic, active far past which its conceptualists like to hold in balance with the reach of time right up to the present, but our past; the mortal past. Much of it will be remembered, in records, and writings - but there is a point, as with Mikhail Pletnev's mountains of classical music, at which one has moved out of the tradition, and it is simply no longer there as it once was: it shifts away from its initial geometry: it becomes conscious of its past: the pathos becomes the whole affair. This is a transition event of deep weight for this country: the end of traditional Aboriginal time. Is it a subject, yet, for art, or writing?

Lectures, like conventional stories, have conclusions, still points where their chains of suggestion and argument make sense, and come to rest: but I feel a scepticism in the face of closure, and I prefer to leave you with a set of suppositions, of thoughts about the structure of writing: notions that belong more to the domain of life than proof or logic. I have the sense that several of the subjects I have touched on are connected, in subterranean ways: that much of the most poignant writing in Australia comes from the Northern frontier, where unease and shadow lie; that the novel is a form without strong local purchase in this landscape; and that there is a provisional tone about much in today's Australian literature, for all its fecundity and respectable abundance, and that this tone - as an echo to a voice - is linked to the tales, and the ways of telling, that existed in the country before, and that are absent today.

My aim has been to bring you to the place where I now stand, mid-way through a book about the deserts, and the Pilbara, and the memories they hold; mid-way through a smoky, deceptive dry season, when the air of the north is thick with incandescent splinters of bloodwood and stringybark, mid-way through a life of words, words written in a vain bid to cheat oblivion. Often I have thought a writer in the northern landscape, or the ranges of the inland, should seek to learn from the patterns that lie around us: I have dreamed of writing a book with the structure of a eucalypt leaf, or the phyllode of a desert oak; or with the repeating pattern of a migrating bird's journeys. 
Often the chain of my ideas leads me back to Colin Roderick's dauntless explorer, Leichhardt, whose first overland expedition brought him across the stone country escarpment, down into the river plains of Kakadu, on his own long march towards the northern outpost of his day, Port Essington. Leichhardt descended to those plains of promise on December 7th 1845, a time of furnace heat and high humidity, and directed his course towards a distant mountain, across a blacksoil wetland thick with grasses. "We saw many columns of dust raised by whirlwinds," he writes, "and again mistook them for the smoke of so many fires of the natives. But we soon observed that they moved in a certain direction, and that new columns rose as those already formed drew off' - and when he and the expedition's remaining members came nearer, and eventually passed between the columns, it seemed to Leichhardt as if the giant spirits of the plain were holding a stately dance around him, although his scientific eye soon saw the bare soil from a late fire that was giving birth to those willy-willys and setting them on their dance across the landscape. And so he advanced, decoding the country and populating it with spirits as he went. I imagine Leichhardt's last days, in some inland desert, of dunes, and meandering flood-out coolibahs, and I tell myself he would recognise the two aspects of the Australian bush that mean the most to me: its weight, its heavy press of imagined presences and memories; and its light, its blazing, revealing light, which seems to hold the promise of a world beyond the sun. And I picture him advancing towards death, down trackless paths, as we all must, the weight of the future bearing down on him, the light of words ashimmer in his eyes.

Thankyou for listening to me with such patience as I have sketched out the stages of this journey; thank you for listening so long. 